\title{
Possible association between the androgen receptor gene and autism spectrum disorder
}

Susanne Henningsson ${ }^{1 *}$, Lina Jonsson ${ }^{1}$, Elin Ljunggren ${ }^{1}$, Lars Westberg ${ }^{1}$, Carina Gillberg 2 , Maria Råstam², Henrik Anckarsäter ${ }^{3}$, Gudrun Nygren ${ }^{2}$, Mikael Landén ${ }^{4}$, Kent Thuresson ${ }^{5}$, Catalina Betancur ${ }^{6,7}$, Marion Leboyer $^{8,9,10}$, Christopher Gillberg ${ }^{2}$, Elias Eriksson ${ }^{1}$, Jonas Melke ${ }^{1}$

${ }^{1}$ Institute of Neuroscience and Physiology, Department of Pharmacology, Gothenburg University, Sweden. 2Institute of Neuroscience and Physiology, Child and Adolescent Psychiatry, Gothenburg University, Gothenburg, Sweden. ${ }^{3}$ Forensic Psychiatry, Universities of Lund and Gothenburg, Sweden. ${ }^{4}$ Stockholm Center for Psychiatric Research, Karolinska Institutet, Stockholm, Sweden. ${ }^{5}$ Institute of Neuroscience and Physiology, Department of Neurochemistry and Psychiatry, Neuropsychiatric unit of Mölndals hospital at the University of Gothenburg, Sweden. ${ }^{\circ}$ INSERM U513, Paris, France. ${ }^{7}$ Université Pierre et Marie Curie, Paris, France. 8INSERM, Unité 841; IMRB, Department of Genetics, Psychiatry Genetic, Créteil, F-94000, France. 'Université Paris 12, Faculté de Médecine, IFR10, Créteil, F-94000, France. ${ }^{10}$ AP-HP, Groupe Henri Mondor-Albert Chenevier, Pôle de psychiatrie, Créteil, F-94000, France.

6INSERM U513, Paris, France. "Université Pierre et Marie Curie, Paris, France

*Corresponding author: Susanne Henningsson, Box 431, 40530 Göteborg, Sweden; phone number: +46 31

7863413; fax number: +46 31 7863065; e-mail address: susanne.henningsson@pharm.gu.se

Short title: Association between androgen receptor gene and autism

\section{Summary}

Autism is a highly heritable disorder but the specific genes involved remain largely unknown. The higher prevalence of autism in men than in women, in conjunction with a number of other observations, has led to the suggestion that prenatal brain exposure to androgens may be of importance for the development of this condition. Prompted by this hypothesis, we investigated the potential influence of variation in the androgen receptor (AR) gene on the susceptibility for autism. To this end, 267 subjects with autism spectrum disorder and 617 controls were genotyped for three polymorphisms in exon 1 of the AR gene: the CAG repeat, the GGN repeat and the rs6152 SNP. In addition, parents and affected siblings were genotyped for 118 and 32 of the cases, respectively. Case-control comparisons revealed higher prevalence of short CAG alleles as well as of the A allele of the rs6152 SNP in female cases than in controls, but revealed no significant differences with respect to the GGN repeat. Analysis of the 118 families using transmission disequilibrium test, on the other hand, suggested an association with the GGN polymorphism, the rare 20-repeat allele being undertransmitted to male cases and the 23-repeat allele being overtransmitted to female cases. Sequencing of the AR gene in 46 patients revealed no mutations or rare variants. The results lend some support for an influence of the studied polymorphisms on the susceptibility for autism, but argue against the possibility that mutations in the AR gene are common in subjects with this condition.

Key words: autism; androgens; testosterone; polymorphism; CAG repeat; GGN repeat; rs6152

\section{Introduction}

Autism is a disorder with early onset that is characterized by impairments of social relatedness and communication, repetitive behaviors, abnormal movements, and sensory dysfunction (Bailey et al., 1996), and that is often but not always associated with mental retardation (MR). Twin studies have demonstrated a much higher concordance for autism in monozygotic $(>70 \%)$ than in dizygotic twins $(0-10 \%)$, suggesting genetic factors to play a major role in the etiology (Bailey et al., 1995; Steffenburg et al., 1989). Certain monogenic causes of autism are well known, such as fragile $\mathrm{X}$ syndrome, Rett syndrome and tuberous sclerosis, and recently certain rare de novo mutations and copy number variations associated with enhanced risk for autism were identified (Durand et al., 2007; Jamain et al., 2003; Sebat et al., 2007) . It is likely that common variants in susceptibility genes, exerting merely a modest influence on autism risk, are also of importance, although no such variants have as yet been proven beyond doubt to be associated with this condition.

Several lines of evidence suggest a role for androgens in the etiology of autism, presumably exerted during prenatal brain development, (Baron-Cohen et al., 2005): (1) The prevalence of autism in men is three to four times higher than in women (Ellefsen et al., 2007; Gillberg, 1984; Latif and Williams, 2007). (2) In a normal population, some of the characteristic features of autism - such as low empathizing and enhanced systemizing are more common in males; in this respect, subjects with autism may hence be described as having an "extreme 
male brain" (Baron-Cohen et al., 2005; Gillberg et al., 1984; Wing, 1981). (3) Both direct (assessment of androgen levels) and indirect (assessment of the ratio between the second and fourth digit as a marker for prenatal androgen exposure) (Manning et al., 1998) evidence suggests elevated fetal testosterone levels to be associated with autism and autism-related traits (Knickmeyer et al., 2005; Manning et al., 2001; Williams et al., 2003). (4) Girls with congential adrenal hyperplasia, a trait associated with exposure to high prenatal androgens, display autism-like traits to a higher extent than their unaffected sisters (Knickmeyer et al., 2006).

Although the relationship between prenatal androgen exposure and androgen production at adult age is unclear, studies providing preliminary support for the notion that autistic traits are associated with enhanced serum levels of testosterone (Geier and Geier, 2007; Tordjman et al., 1997) may also be taken as support for the notion that autism is indeed associated with enhanced androgenization. In the same vein, one study reports testosteronerelated disorders to be more common in women with autism than in controls (Ingudomnukul et al., 2007).

The androgen receptor $(A R)$ is a ligand-activated transcription factor that belongs to the steroid and thyroid hormone receptor superfamily (Zhou et al., 1994) and is encoded by a gene located on the X chromosome (Xq11-12). Exon 1 of this gene, which encodes the amino-terminal domain of the AR involved in transcriptional activation of downstream genes (Faber et al., 1989), comprises two repeat polymorphisms: a CAG repeat sequence encoding a poly-glutamine stretch and a GGN repeat sequence encoding a poly-glycine stretch. Between these, a synonymous SNP rs6152 (G1733A) - also known as Stu - is situated. Whereas the length of the CAG repeat is inversely correlated with the activity of the AR as a transcription factor (Beilin et al., 2000; Chamberlain et al., 1994), findings on the functional consequences of the GGN repeat polymorphism are inconsistent (Brockschmidt et al., 2007; Ding et al., 2005). The functional effect of the SNP rs6152 has not yet been studied.

In the present study, these three polymorphisms in the $A R$ were studied for possible association with autism using both case-control and family-based association tests. In addition, mutation screening of coding and regulatory regions of the $A R$ was performed in a subset of patients.

\section{Methods}

Study population

In total, 267 subjects meeting DSM-IV criteria for autism spectrum disorder were genotyped. The individuals came from two different cohorts: (a) 204 were recruited from the Paris Autism Research International Sib-pair (PARIS) study (Philippe et al., 1999), and (b) 63 came from a separate Swedish cohort. All individuals in cohort (a) had been given a full clinical research protocol assessment including collateral diagnostic interviews, personal assessment, psychological testing and laboratory examinations to exclude associated genetic disorders, see (Philippe et al., 1999). The individuals in cohort (b) had been examined by an experienced neuropsychiatrist in an in-patient setting and diagnosed according to strict DSM-IV-criteria on the basis of this examination and psychological testing. In addition, DNA from 118 parents and 32 affected sibs of the PARIS subjects was obtained and analyzed.

In the PARIS study, the vast majority was of either French (50\%) or Swedish (25\%) origin, with $92 \%$ being Caucasian. Of the 118 subjects from the PARIS study included in the family-based analysis, 35 were female. Seventy-eight $\%$ of the male and $74 \%$ of the female subjects of this subgroup had mental retardation (MR). Mean age was $12 \pm 7$ years.

Of the remaining 86 subjects from the PARIS study, 20 were women. Fifty-four $\%$ of the male and $59 \%$ of the female subjects of this subgroup had MR. Ages were in the interval 18-60 years. Cases not meeting criteria for MR were categorized as "high-functioning".

Of the 63 subjects from the separate Swedish sample, all were of Swedish origin and all had MR. The men $(n=39)$ were between 16 and 60 years old (mean: 43) and the women were between 17 and 58 years old (mean: 34).

The control sample $(n=617)$ used for the case-control association studies consisted of 100 French (41 women) and 517 Swedish subjects (270 women). The French controls were recruited among blood donors at the PitiéSalpêtrière hospital in Paris. They were all of European descent and inclusion was made after interviews with the Diagnostic Interview for Genetic Studies and the Family Interview for Genetic Studies to confirm the absence of both personal and family history of major psychiatric disorders. Mean age was $43 \pm 13$ years. The Swedish 
population was drafted from the general population. The women were born on uneven days in 1956 (Rosmond and Bjorntorp, 1998) and were 42 years old at evaluation. The men were a subsample of all men born during the first 6 months in 1944 and living in Gothenburg, and were 51 years old at evaluation. More detailed information has been previously reported (Rosmond et al., 1998).

These samples were used to conduct three analyses. First, a case-control study was undertaken, comprising all cases and controls. For subjects belonging to sib-pairs $(n=32)$, one sib was randomly chosen by means of the generation of a random vector. Second, a case-control analysis where all individuals were included and relatedness was controlled for, was conducted. And third, a family-based association study was performed.

Using the results from the genotyping of the CAG and GGN repeats in the family-based association study, one of the siblings from affected sib-pairs sharing one or two alleles of the $A R$ were selected for mutation screening $(n=13)$. Thirty-three other patients were selected randomly to generate a final sample of 46 subjects ( 3 women) for this part of the study, two of whom had normal IQ.

The study was conducted in accordance with the declaration of Helsinki and approved by the local Research Ethics Boards. Written informed consent was obtained from parents or legal guardians, and, if possible (i.e. if the patient did not have severe MR) from patients, as well as from controls.

\section{Genotyping and mutation screening}

In the PARIS-study, DNA was extracted from blood leukocytes $(\approx 50 \%)$ or lymphoblastoid cell lines $(\approx 50 \%)$. In the separate Swedish population, DNA was extracted from blood samples from all subjects. Genotyping of repeat polymorphisms was performed by means of electrophoreses using an ABI 3730 genetic analyzer (Applied Biosystems, Foster City, CA). The number of repeats corresponding to fragment length was verified using sequencing. Genotyping of the SNP was performed by pyrosequencing technology (Pyrosequencing AB, Uppsala, Sweden). Except for fragments (20-30bp) surrounding the two microsatellites in exon one, all eight exons, intron-exon boundaries and the 600 bp upstream of the transcription start site containing the promoter (Tilley et al., 1990) were successfully sequenced using the BigDye Terminator Cycle Sequencing Kit (V3.1, Applied Biosystems). Samples were then subjected to electrophoresis, using the ABI 3730 genetic analyzer. For primer sequences and PCR conditions used in genotyping and mutation screening, see Supplementary Table 1.

\section{Classification of genolypes}

For the repeats, alleles were classified into one of four possible length categories: rare short (CAG: 7-19 repeat units, GGN: 12-22), common short (CAG: 20-21, GGN: 23), common long (CAG: 22-23, GGN: 24) and rare long (CAG: 24-33, GGN: 25-28). Although not possible due to the uneven distribution of alleles, the selection of cutoffs had the purpose of creating equal-sized groups. The two short and the two long categories were merged to create one short (S) and one long (L) length category, respectively. These cutoffs corresponded to the median repeat lengths in controls. The categorizations were used both for the case-control analyses and the family-based association tests.

\section{Statistical analyses}

In the case-control analyses, the groups were compared with respect to allelic length using Independent-samples $\mathrm{t}$-tests, and with respect to distributions of length categories and of genotypes derived from dichotomized alleles using likelihood ratio based chi-square tests. One proband was chosen randomly from each affected sib-pair family; when sexes were analyzed separately, the proband of the relevant sex was always chosen from mixed-sex sib-pairs. Generalized estimating equations (GEE), where both individuals from sib-pairs could be included and dependencies controlled for, were performed with case-control status as the dependent binomial variable, a logit link function, and the polymorphisms as independent variables. Analyses of possible two-locus effects were conducted by means of GEE. These analyses were performed using SPSS, version 15.0.

Multiallelic Transmission Disequilibrium Tests (mTDT) were performed using the mTDT program in the gap package in $R$, producing the Stuart chi-square statistics and corresponding $p$-values using 10.000 simulations. TDTs were also performed for the grouping of the alleles into short and long repeat lengths. In addition, each length category was tested against all other alleles grouped together.

Because the $A \mathrm{R}$ is located on the $\mathrm{X}$ chromosome, the haplotype of every $\mathrm{XY}$ individual, and also for most mothers of probands, could be unambiguously determined. To shed light on the extent of linkage disequilibrium (LD) between the three polymorphisms, haplotype frequencies were assessed for the subgroup of individuals for 
which haplotypes did not have to be estimated. LD measures are hence based on observed and not estimated haplotypes in the subgroup consisting of male controls and parents of probands.

The multiallelic modification of Lewinton's D', a weighted average of the D'values, the weights being the products of the corresponding allele frequencies, is given as LD measure. The extent of LD was determined by means of chi-square tests; the sum of squared $\mathrm{D}$-values divided by the product of the corresponding allele frequencies and multiplied by the number of haplotypes in the sample is Chi-square distributed with $(n-1) \cdot(m-1)$ degrees of freedom, where $n$ and $m$ are the number of alleles for the two loci. Alleles with frequencies less than $1 \%$ were excluded.

\section{Results}

\section{Allele and haplotype frequencies}

The distributions of the repeat alleles are displayed in Figure 1. The allele frequency was 0.14 for the $A$ allele of rs6152. Haplotypes could be unambiguously determined in men and in most parents of probands. Haplotype frequencies are displayed in Table 1. The D' between the CAG and GGN repeats was $0.25(p>0.5)$, between the CAG repeat and rs6152 it was $0.44(p<0.001)$ and between the rs6152 and the GGN repeat it was 0.72 $(\phi<0.001)$. The rare A allele of the rs6152 most often occurred on the same haplotype as the common 24-repeat allele of the GGN (74 times against 15 times on other GGN alleles). Furthermore, the A allele always occurred with CAG alleles of lengths 18-22 repeats, preferentially with 18- or 21-repeat alleles, both of which belong to the short category (see Table 1 for haplotype frequencies).

\section{Case-control association study}

The mean CAG allele length was shorter in patients than in controls, and the $S$ allele frequency was significantly higher in cases than in controls. After splitting for gender, this difference was found to be significant only in females, among whom, in addition, cases had a higher frequency of the SS genotype (Table 2). There was also a trend for higher frequency of the two shorter allele categories in females when the allelic length was divided into four categories (Table 2). No significant differences were found for the GGN repeat. The rs6152 displayed higher frequency of the rare A-containing genotypes in female cases compared to female controls (Table 2).

The GEE, utilizing all individuals including both members of affected sib-pairs, produced similar results of higher frequency of the $S$ allele $(p=0.02, \mathrm{OR}=1.6$ for the $S$ compared to the $\mathrm{L}$ allele) and of the SS genotype when treating genotype as a covariate $(p=0.03, \mathrm{OR}=1.6)$ in females with autism. There was also an association between the rs6152 A allele and autism in females using GEE ( $p=0.03, \mathrm{OR}=1.7$ for presence of the $\mathrm{A}$ allele compared to the GG genotype). No trend was observed for the GGN repeat.

Separate analysis of high-functioning subjects was not deemed meaningful due to the low number of cases $(n=46$ for men and $n=13$ for women). Removing the high-functioning cases did not reduce the level of significance, neither for the CAG repeat, nor for the rs6152 SNP (data not shown).

No two-locus effects of the polymorphisms were found when analyzing combinations of genotypes (data not shown). When the CAG repeat and the rs6152 SNP were entered in the same GEE model, only the CAG repeat had a significant effect on autism risk in women.

\section{Family-based association study}

When considering the four allele length categories, 82,31 and 66 families were informative for multiallelic TDT - since they comprised heterozygous mothers - for the CAG repeat, the rs6152 and the GGN repeat of the $A R$, respectively.

Neither the TDTs for the CAG repeat, nor the TDTs for the rs6152 polymorphism, revealed excess transmission of any allele to probands from heterozygous parents (Table 3). The GGN repeat showed undertransmission of the rare short allele category to probands from mothers carrying one such allele and one of the longer alleles, an effect that was found to be prevalent only when considering transmissions to males (Table 3), and to be entirely due to undertransmission of the 20-repeat allele (transmitted 7 times and non-transmitted once only). The 20-repeat GGN allele always occurred on a haplotype with the rs6152 G allele. A significant overtransmission of the common short 23-repeat allele of the GGN polymorphism to female probands was found (Table 3). 
Because of the indication of an association between the CAG repeat and autism in women, the short CAG allele categories were further investigated in the family sample, revealing that the 20-repeat allele was the only allele that was significantly overtransmitted to female probands $(\phi=0.02$, transmitted 8 times and non-transmitted only once).

\section{Mutation screening}

Sequencing of the $A R$ did not reveal any previously unknown polymorphisms or rare variants.

\section{Discussion}

Although the results from the case-control study and the family-based study were not unequivocal, they do lend support for the notion that variants in the gene encoding the AR may influence the susceptibility for autism in women. In contrast, no support was obtained for the hypothesis that rare mutations in this gene are common in subjects with autism.

Two previous studies have assessed microsatellites in the $A R$ to address the issue of altered X-inactivation patterns in autism (Gong et al., 2008; Talebizadeh et al., 2005), but they did not investigate the possible association between repeat length and the studied disorder. This is, thus, to our knowledge, the first study presenting results from association studies of the $A R$ in autism. This is somewhat surprising since this gene is an obvious candidate gene for autism, due to its position on the X chromosome, the skewed male-to-female prevalence of autism and the suggested relationship between autism and the prenatal influence of androgens on brain development (Baron-Cohen et al., 2005; Geier and Geier, 2007; Gillberg and Schaumann, 1982;

Knickmeyer et al., 2005; Leboyer et al., 1988; Manning et al., 2001; Tordjman et al., 1997; Williams et al., 2003; Wing, 1981).

The length of the CAG repeat is inversely correlated with the activity of the AR (Beilin et al., 2000; Chamberlain et al., 1994), and short repeat lengths have previously been shown to increase prenatal androgen sensitivity as measured by the ratio between the second and fourth digit (Manning et al, 2003). It has also been shown that, in women, short CAG repeats are associated with higher testosterone levels (Ibanez et al., 2003; Westberg et al., 2001) as well as with higher risk of conditions related to hyperandrogenicity (Shah et al., 2008). The outcome of our case-control association study, indicating a higher prevalence of short CAG repeat alleles in female patients, is hence consistent with the "extreme male brain" theory of autism suggesting enhanced prenatal influence of androgens on brain development to be a factor of importance for the development of this condition (BaronCohen et al., 2005). When based on a categorization of CAG repeats according to length, the TDT test did not reveal a significant influence of the CAG repeat on risk for autism, but a post hoc analysis, motivated by the outcome of the case-control study, suggested the short 20-repeat to be overtransmitted to women with autism.

It should be noted that neither the case-control study nor the family-based analysis provided any support for an influence of the CAG repeat in the $A R$ on the risk for autism in males. Obviously, it is not unlikely that men and women differ with respect to the importance of inter-individual differences in prenatal androgen exposure, and that women may be more sensitive to subtle differences in this regard.

The common $\mathrm{G}$ allele of the rs 6152 has previously been associated with androgenetic alopecia in men (Ellis et al., 2007; Ellis et al., 2001; Hillmer et al., 2005; Prodi et al., 2008); this association has however sometimes been proposed to be due to LD with other polymorphisms. When interpreting our finding of an association between the $A$ allele and autism in women, it should be taken into consideration that the $A$ allele occurred on haplotypes with certain CAG repeat alleles only, the majority of which belong to the short category; this observation is in line with previous reports (Saare et al., 2007). Notably, when the two polymorphisms were analyzed simultaneously, the CAG repeat, but not the rs6152, showed an influence on autism risk.

The high LD seen between the SNP and both the CAG and the GGN repeats is consistent with other reports of high LD over the AR (Hillmer et al., 2005; Rexrode et al., 2008); moreover, also in line with previous studies, the two repeats were not in LD (Kittles et al., 2001). In spite of the exclusion of alleles with frequencies smaller than one percent, the power of detecting LD may have been too low because of the large number of alleles.

While the case-control study provided no support for an influence of the GGN repeat polymorphism, the family-based analyses revealed an overtransmission of the 23-repeat allele to female patients and an undertransmission of the 20-repeat allele to males with autism. The possible functional consequences of the GGN repeat polymorphism remain controversial; three studies indicate a positive correlation between GGN 
repeat number and AR activity or protein amount (Brockschmidt et al., 2007; Gao et al., 1996; Werner et al., 2006), one indicates an inverse correlation with AR protein amount (Ding et al., 2005), and one suggests higher activity for the most common 23-repeat allele (Lundin et al., 2007). Studies on androgen-related phenotypes in men, including prostate cancer, infertility and baldness, report different direction of association for the GGN repeat; most but not all studies however indicate that a short repeat length is associated with enhanced androgenicty (Chang et al., 2002; Edwards et al., 1999; Ferlin et al., 2004; Hillmer et al., 2005; Hsing et al., 2000; Lundin et al., 2006). Notably, one study indicating a direction for the relation between the GGN repeat and androgen exposure in women show shorter GGN repeats to be associated with higher androgen activity as illustrated by a smaller risk for endometrial cancer (Sasaki et al., 2005), a finding that is in line with our observation of overtransmission of the common short 23-repeat allele to female cases, considering the androgen theory of autism.

Even when not combined with autism, MR is much more common in men than in women. Since the majority of the subjects included in this study displayed autism combined with MR, the associations observed might obviously reflect an association between the $A R$ and $\mathrm{MR}$ in general rather than between the $A \mathrm{R}$ and autism per se. Indeed, although $A R$ mutations that cause MR have not yet been found (Gottlieb et al., 2004), genetic variation in the $A R$ has been associated with MR (Kooy et al., 1999) and cognitive ability (Yaffe et al., 2003).

Although relatively few patients were screened for mutations, we can exclude a high frequency of rare $A R$ variants in autism. This finding is in line with a previous small negative study (Yan et al., 2004).

In conclusion, our findings support the notion that genetic variation within the $A R$ may influence the susceptibility of autism, hence lending support to the "extreme male brain" theory of autism. However, the results also indicate that this influence may be gender-dependent. Furthermore, our results suggest that rare mutations in the $A R$ are not common in autism.

\section{Acknowledgements}

We are grateful for the skilful assistance of technicians Gunilla Bourghardt and Inger Oscarsson and nurse Carina Algede. This work has been supported by the Swedish Research Council (6588, 8668 and 2006-3449), the Wilhelm and Martina Lundgren Foundation, the INSERM, Fondation Orange and the Brain Power Consortium, and by the Swedish Knowledge Foundation through the Industrial PhD programme in Medical Bioinformatics at the Strategy and Development Office at Karolinska Institutet. We would like to thank The SWEGENE Göteborg Genomics Core Facility platform, funded by a grant from the Knut and Alice Wallenberg Foundation.

\section{References}

Bailey, A., Le Couteur, A., Gottesman, I., Bolton, P., Simonoff, E., Yuzda, E., Rutter, M., 1995. Autism as a strongly genetic disorder: evidence from a British twin study. Psychol Med 25, 63-77.

Bailey, A., Phillips, W., Rutter, M., 1996. Autism: towards an integration of clinical, genetic, neuropsychological, and neurobiological perspectives. J Child Psychol Psychiatry 37, 89-126.

Baron-Cohen, S., Knickmeyer, R. C., Belmonte, M. K., 2005. Sex differences in the brain: implications for explaining autism. Science 310, 819-823.

Beilin, J., Ball, E. M., Favaloro, J. M., Zajac, J. D., 2000. Effect of the androgen receptor CAG repeat polymorphism on transcriptional activity: specificity in prostate and non-prostate cell lines. J Mol Fndocrinol 25, 85-96.

Brockschmidt, F. F., Nothen, M. M., Hillmer, A. M., 2007. The two most common alleles of the coding GGN repeat in the androgen receptor gene cause differences in protein function. J Mol Endocrinol 39, 1-8.

Chamberlain, N. L., Driver, E. D., Miesfeld, R. L., 1994. The length and location of CAG trinucleotide repeats in the androgen receptor $\mathrm{N}$-terminal domain affect transactivation function. Nucleic Acids Res 22, 3181-3186.

Chang, B. L., Zheng, S. L., Hawkins, G. A., Isaacs, S. D., Wiley, K. E., Turner, A., Carpten, J. D., Bleecker, E. R., Walsh, P. C., Trent, J. M., Meyers, D. A., Isaacs, W. B., Xu, J., 2002. Polymorphic GGC repeats in the androgen receptor gene are associated with hereditary and sporadic prostate cancer risk. Hum Genet 110, 122-129.

Ding, D., Xu, L., Menon, M., Reddy, G. P., Barrack, E. R., 2005. Effect of GGC (glycine) repeat length polymorphism in the human androgen receptor on androgen action. Prostate 62, 133-139. 
Durand, C. M., Betancur, C., Boeckers, T. M., Bockmann, J., Chaste, P., Fauchereau, F., Nygren, G., Rastam, M., Gillberg, I. C., Anckarsater, H., Sponheim, E., Goubran-Botros, H., Delorme, R., Chabane, N., Mouren-Simeoni, M. C., de Mas, P., Bieth, E., Roge, B., Heron, D., Burglen, L., Gillberg, C., Leboyer, M., Bourgeron, T., 2007. Mutations in the gene encoding the synaptic scaffolding protein SHANK3 are associated with autism spectrum disorders. Nat Genet 39, 25-27.

Edwards, S. M., Badzioch, M. D., Minter, R., Hamoudi, R., Collins, N., Ardern-Jones, A., Dowe, A., Osborne, S., Kelly, J., Shearer, R., Easton, D. F., Saunders, G. F., Dearnaley, D. P., Eeles, R. A., 1999. Androgen receptor polymorphisms: association with prostate cancer risk, relapse and overall survival. Int J Cancer 84, 458-465.

Ellefsen, A., Kampmann, H., Billstedt, E., Gillberg, I. C., Gillberg, C., 2007. Autism in the Faroe Islands: an epidemiological study. J Autism Dev Disord 37, 437-444.

Ellis, J. A., Scurrah, K. J., Cobb, J. E., Zaloumis, S. G., Duncan, A. E., Harrap, S. B., 2007. Baldness and the androgen receptor: the AR polyglycine repeat polymorphism does not confer susceptibility to androgenetic alopecia. Hum Genet 121, 451-457.

Ellis, J. A., Stebbing, M., Harrap, S. B., 2001. Polymorphism of the androgen receptor gene is associated with male pattern baldness. J Invest Dermatol 116, 452-455.

Faber, P. W., Kuiper, G. G., van Rooij, H. C., van der Korput, J. A., Brinkmann, A. O., Trapman, J., 1989. The N-terminal domain of the human androgen receptor is encoded by one, large exon. Mol Cell Endocrinol 61, 257-262.

Ferlin, A., Bartoloni, L., Rizzo, G., Roverato, A., Garolla, A., Foresta, C., 2004. Androgen receptor gene CAG and GGC repeat lengths in idiopathic male infertility. Mol Hum Reprod 10, 417-421.

Gao, T., Marcelli, M., McPhaul, M. J., 1996. Transcriptional activation and transient expression of the human androgen receptor. J Steroid Biochem Mol Biol 59, 9-20.

Geier, D. A., Geier, M. R., 2007. A prospective assessment of androgen levels in patients with autistic spectrum disorders: biochemical underpinnings and suggested therapies. Neuro Endocrinol Lett 28, 565-573.

Gillberg, C., 1984. Infantile autism and other childhood psychoses in a Swedish urban region. Epidemiological aspects. J Child Psychol Psychiatry 25, 35-43.

Gillberg, C., Schaumann, H., 1982. Social class and infantile autism. J Autism Dev Disord 12, 223-228.

Gillberg, C., Winnergard, I., Wahlstrom, J., 1984. The sex chromosomes--one key to autism? An XYY case of infantile autism. Appl Res Ment Retard 5, 353-360.

Gong, X., Bacchelli, E., Blasi, F., Toma, C., Betancur, C., Chaste, P., Delorme, R., Durand, C. M., Fauchereau, F., Botros, H. G., Leboyer, M., Mouren-Simeoni, M. C., Nygren, G., Anckarsater, H., Rastam, M., Gillberg, I. C., Gillberg, C., Moreno-De-Luca, D., Carone, S., Nummela, I., Rossi, M., Battaglia, A., Jarvela, I., Maestrini, E., Bourgeron, T., 2008. Analysis of X chromosome inactivation in autism spectrum disorders. Am J Med Genet B Neuropsychiatr Genet.

Gottlieb, B., Beitel, L. K., Wu, J. H., Trifiro, M., 2004. The androgen receptor gene mutations database (ARDB): 2004 update. Hum Mutat 23, 527-533.

Hillmer, A. M., Hanneken, S., Ritzmann, S., Becker, T., Freudenberg, J., Brockschmidt, F. F., Flaquer, A., Freudenberg-Hua, Y., Jamra, R. A., Metzen, C., Heyn, U., Schweiger, N., Betz, R. C., Blaumeiser, B., Hampe, J., Schreiber, S., Schulze, T. G., Hennies, H. C., Schumacher, J., Propping, P., Ruzicka, T., Cichon, S., Wienker, T. F., Kruse, R., Nothen, M. M., 2005. Genetic variation in the human androgen receptor gene is the major determinant of common early-onset androgenetic alopecia. Am J Hum Genet 77, 140-148.

Hsing, A. W., Gao, Y. T., Wu, G., Wang, X., Deng, J., Chen, Y. L., Sesterhenn, I. A., Mostofi, F. K., Benichou, J., Chang, C., 2000. Polymorphic CAG and GGN repeat lengths in the androgen receptor gene and prostate cancer risk: a population-based case-control study in China. Cancer Res 60, 5111-5116.

Ibanez, L., Ong, K. K., Mongan, N., Jaaskelainen, J., Marcos, M. V., Hughes, I. A., De Zegher, F., Dunger, D. B., 2003. Androgen receptor gene CAG repeat polymorphism in the development of ovarian hyperandrogenism. $\mathrm{J}$ Clin Endocrinol Metab 88, 3333-3338. 
Ingudomnukul, E., Baron-Cohen, S., Wheelwright, S., Knickmeyer, R., 2007. Elevated rates of testosteronerelated disorders in women with autism spectrum conditions. Horm Behav.

Jamain, S., Quach, H., Betancur, C., Rastam, M., Colineaux, C., Gillberg, I. C., Soderstrom, H., Giros, B., Leboyer, M., Gillberg, C., Bourgeron, T., 2003. Mutations of the X-linked genes encoding neuroligins NLGN3 and NLGN4 are associated with autism. Nat Genet 34, 27-29.

Kittles, R. A., Young, D., Weinrich, S., Hudson, J., Argyropoulos, G., Ukoli, F., Adams-Campbell, L., Dunston, G. M., 2001. Extent of linkage disequilibrium between the androgen receptor gene CAG and GGC repeats in human populations: implications for prostate cancer risk. Hum Genet 109, 253-261.

Knickmeyer, R., Baron-Cohen, S., Fane, B. A., Wheelwright, S., Mathews, G. A., Conway, G. S., Brook, C. G., Hines, M., 2006. Androgens and autistic traits: A study of individuals with congenital adrenal hyperplasia. Horm Behav 50, 148-153.

Knickmeyer, R., Baron-Cohen, S., Raggatt, P., Taylor, K., 2005. Foetal testosterone, social relationships, and restricted interests in children. J Child Psychol Psychiatry 46, 198-210.

Kooy, R. F., Reyniers, E., Storm, K., Vits, L., van Velzen, D., de Ruiter, P. E., Brinkmann, A. O., de Paepe, A., Willems, P. J., 1999. CAG repeat contraction in the androgen receptor gene in three brothers with mental retardation. Am J Med Genet 85, 209-213.

Latif, A. H., Williams, W. R., 2007. Diagnostic trends in autistic spectrum disorders in the South Wales valleys. Autism 11, 479-487.

Leboyer, M., Osherson, D. N., Nosten, M., Roubertoux, P., 1988. Is autism associated with anomalous dominance? J Autism Dev Disord 18, 539-551.

Lundin, K. B., Giwercman, A., Dizeyi, N., Giwercman, Y. L., 2007. Functional in vitro characterisation of the androgen receptor GGN polymorphism. Mol Cell Endocrinol 264, 184-187.

Lundin, K. B., Giwercman, Y. L., Rylander, L., Hagmar, L., Giwercman, A., 2006. Androgen receptor gene GGN repeat length and reproductive characteristics in young Swedish men. Eur J Endocrinol 155, 347-354.

Manning, J. T., Baron-Cohen, S., Wheelwright, S., Sanders, G., 2001. The 2nd to 4th digit ratio and autism. Dev Med Child Neurol 43, 160-164.

Manning, J. T., Scutt, D., Wilson, J., Lewis-Jones, D. I., 1998. The ratio of 2nd to 4th digit length: a predictor of sperm numbers and concentrations of testosterone, luteinizing hormone and oestrogen. Hum Reprod 13, 30003004.

Philippe, A., Martinez, M., Guilloud-Bataille, M., Gillberg, C., Rastam, M., Sponheim, E., Coleman, M., Zappella, M., Aschauer, H., Van Maldergem, L., Penet, C., Feingold, J., Brice, A., Leboyer, M., 1999. Genome-wide scan for autism susceptibility genes. Paris Autism Research International Sibpair Study. Hum Mol Genet 8, 805-812.

Prodi, D. A., Pirastu, N., Maninchedda, G., Sassu, A., Picciau, A., Palmas, M. A., Mossa, A., Persico, I., Adamo, M., Angius, A., Pirastu, M., 2008. EDA2R Is Associated with Androgenetic Alopecia. J Invest Dermatol.

Rexrode, K. M., Ridker, P. M., Hegener, H. H., Buring, J. E., Manson, J. E., Zee, R. Y., 2008. Genetic variation of the androgen receptor and risk of myocardial infarction and ischemic stroke in women. Stroke 39, 1590-1592.

Rosmond, R., Bjorntorp, P., 1998. Psychiatric ill-health of women and its relationship to obesity and body fat distribution. Obes Res 6, 338-345.

Rosmond, R., Dallman, M. F., Bjorntorp, P., 1998. Stress-related cortisol secretion in men: relationships with abdominal obesity and endocrine, metabolic and hemodynamic abnormalities. J Clin Endocrinol Metab 83, 18531859 .

Saare, M., Belousova, A., Punab, M., Peters, M., Haller, K., Ausmees, K., Poolamets, O., Karro, H., Metspalu, A., Salumets, A., 2007. Androgen receptor gene haplotype is associated with male infertility. Int J Androl.

Sasaki, M., Karube, A., Karube, Y., Watari, M., Sakuragi, N., Fujimoto, S., Dahiya, R., 2005. GGC and StuI polymorphism on the androgen receptor gene in endometrial cancer patients. Biochem Biophys Res Commun 329, 100-104. 
Sebat, J., Lakshmi, B., Malhotra, D., Troge, J., Lese-Martin, C., Walsh, T., Yamrom, B., Yoon, S., Krasnitz, A., Kendall, J., Leotta, A., Pai, D., Zhang, R., Lee, Y. H., Hicks, J., Spence, S. J., Lee, A. T., Puura, K., Lehtimaki, T., Ledbetter, D., Gregersen, P. K., Bregman, J., Sutcliffe, J. S., Jobanputra, V., Chung, W., Warburton, D., King, M. C., Skuse, D., Geschwind, D. H., Gilliam, T. C., Ye, K., Wigler, M., 2007. Strong association of de novo copy number mutations with autism. Science 316, 445-449.

Shah, N. A., Antoine, H. J., Pall, M., Taylor, K. D., Azziz, R., Goodarzi, M. O., 2008. Association of Androgen Receptor CAG Repeat Polymorphism and Polycystic Ovary Syndrome. J Clin Endocrinol Metab 93, $1939-1945$.

Steffenburg, S., Gillberg, C., Hellgren, L., Andersson, L., Gillberg, I. C., Jakobsson, G., Bohman, M., 1989. A twin study of autism in Denmark, Finland, Iceland, Norway and Sweden. J Child Psychol Psychiatry 30, 405-416.

Talebizadeh, Z., Bittel, D. C., Veatch, O. J., Kibiryeva, N., Butler, M. G., 2005. Brief report: non-random X chromosome inactivation in females with autism. J Autism Dev Disord 35, 675-681.

Tilley, W. D., Marcelli, M., McPhaul, M. J., 1990. Expression of the human androgen receptor gene utilizes a common promoter in diverse human tissues and cell lines. J Biol Chem 265, 13776-13781.

Tordjman, S., Ferrari, P., Sulmont, V., Duyme, M., Roubertoux, P., 1997. Androgenic activity in autism. Am J Psychiatry 154, 1626-1627.

Werner, R., Holterhus, P. M., Binder, G., Schwarz, H. P., Morlot, M., Struve, D., Marschke, C., Hiort, O., 2006. The A645D mutation in the hinge region of the human androgen receptor (AR) gene modulates AR activity, depending on the context of the polymorphic glutamine and glycine repeats. J Clin Endocrinol Metab 91, 35153520 .

Westberg, L., Baghaei, F., Rosmond, R., Hellstrand, M., Landen, M., Jansson, M., Holm, G., Bjorntorp, P., Eriksson, E., 2001. Polymorphisms of the androgen receptor gene and the estrogen receptor beta gene are associated with androgen levels in women. J Clin Endocrinol Metab 86, 2562-2568.

Williams, J. H., Greenhalgh, K. D., Manning, J. T., 2003. Second to fourth finger ratio and possible precursors of developmental psychopathology in preschool children. Early Hum Dev 72, 57-65.

Wing, L., 1981. Sex ratios in early childhood autism and related conditions. Psychiatry Res 5, 129-137.

Yaffe, K., Edwards, E. R., Lui, L. Y., Zmuda, J. M., Ferrell, R. E., Cauley, J. A., 2003. Androgen receptor CAG repeat polymorphism is associated with cognitive function in older men. Biol Psychiatry 54, 943-946.

Yan, J., Feng, J., Goldman, D., Cook, E. H., Jr., Craddock, N., Jones, I. R., Heston, L. L., Sommer, S. S., 2004. Mutation scanning of the androgen receptor gene in patients with psychiatric disorders reveals highly conserved variants in alcoholic and phobia patients. Psychiatr Genet 14, 57-60.

Zhou, Z. X., Wong, C. I., Sar, M., Wilson, E. M., 1994. The androgen receptor: an overview. Recent Prog Horm Res 49, 249-274. 